\title{
Effects of Dexamethasone on Pulmonary Oxygenation Impairments in Therapeutic Hypothermia for Patients with Traumatic Brain Injury
}

*Mayuki Aibiki, Kensuke Umakoshi, Saori Ohtsubo, Satoshi Kikuchi, Hironori Matsumoto, Muneaki Ohshita, Soichi Maekawa and Takashi Nishiyama

Department of Emergency Medicine, School of Medicine, Ehime University, Japan

\begin{abstract}
Objectives: We studied retrospectively to examine differences in the occurrence rate of pneumonia and the time-course changes in pulmonary oxygenation between hypothermic and normothermic therapies with or without dexamethasone (D) administration in patients with traumatic brain injury (TBI).

Design: A retrospective observational study.

Setting: Two university hospitals.

Subjects and Methods: In consecutive TBI patients $(\mathrm{GCS} \leq 8)$ treated with hypothermic $\left(\mathrm{N}=23,32-33^{\circ} \mathrm{C}\right)$ or normothermic $\left(\mathrm{N}=16,36-37.5^{\circ} \mathrm{C}\right)$ therapy, the occurrence rate of pneumonia, $\mathrm{PaO} 2 / \mathrm{FIO} 2(\mathrm{P} / \mathrm{F})$ ratios and $\mathrm{C}$-reactive protein (CRP) levels were examined. The comparisons were made among hypothermic and normothermic groups with or without $D$ administration. In several patients in both groups, neutrophil functions were examined. Data were analyzed with ANOVA followed by Sheffe's F-test, Mann-Whitney U-test, Kruskal-Wallis tests or chi-squared test $(p<0.05)$ as appropriate.
\end{abstract}

Results: The occurrence rate of pneumonia in a hypothermic group with $D$ administration was significantly lower than in a hypothermic group without $\mathrm{D}$. In the hypothermic group without $\mathrm{D}$ treatment, CRP elevation during the rewarming phase occurred, which was followed by more severe P/F ratio deteriorations as compared to the hypothermic group given D. Neutrophil phagocytic functions in hypothermic patients without D were activated around $35^{\circ} \mathrm{C}$, which were followed by marked decreases in pulmonary oxygen. In contrast, phagocytic function in a hypothermic patient receiving $\mathrm{D}$ was depressed, but without $\mathrm{P} / \mathrm{F}$ ratios below 280 .

Conclusion: This study poses hypotheses that neutrophils play a role in the pulmonary oxygenation impairment in hypothermic therapy for TBI patients, and that dexamethasone improves the pulmonary complications in therapeutic hypothermia.

Keywords: Complication; Dexamethasone; Hypothermic therapy; Neutrophil; Oxygenation

\section{Introduction}

NABISH (National Acute Brain Injury Study for Hypothermia) and NABISH II failed to show benefits of hypothermic therapy for patients with traumatic brain injury (TBI); in their study the number of patients in hypothermic groups having systemic complications including pneumonia has been reported to be larger than that in normothermic groups [1]. A Japanese multi-center trial of hypothermia for TBI showed that the occurrence rate of pneumonia in hypothermic group was much higher than that in normothermia (49\% in hypothermia versus $15 \%$ in normothermia) [2]. It has been suggested that hypothermic therapy performing for a period longer than 72 hours may result in an increased occurrence rate of pneumonia [3]. However, we demonstrated that in TBI patients, hypothermic therapy even for 72-96 hours did not show any significant differences in the rate of pneumonia as compared to normothermic therapy $[4,5]$. In these previous studies, dexamethasone (D) was used for reducing brain swelling, though not being used at the present time according to a guideline of steroid usage for TBI [6]. Thereafter, we reported in a preliminary study that after discontinuing D, TBI patients undergoing therapeutic hypothermia had an increase in the rate of pneumonia in our hospital [7].

Polymorphonuclear leukocytes (PMNs) have been shown to play a role in the development of tissue injury due to LPS-induced interleukin-8 production after the rewarming from hypothermic state in vitro [8]. Glucocorticoid, a modulator for neutrophil functions [9], has been demonstrated to prevent the late-phase occurrence of acute lung injury in critical trauma patients [10]. We have reported in a preliminary study that neutrophil phagocytic functions in brain-injured patients undergoing hypothermic therapy, if $\mathrm{D}$ was not administered, were activated during the rewarming phase and their pulmonary oxygenations were profoundly impaired, whereas phagocytic functions in patients with steroid administrations were depressed but no severe deteriorations of oxygenation occurred during the course [7]. Thus, it is possible that an attenuation of the neutrophil functions by steroid has certain beneficial effects on lung injury during the hypothermic therapy.

On the other hand, several papers reported that there were no benefits of methyl prednisolone in the neurological prognosis of traumatic brain-injured patients [6], or even a rise in the risk of death within two weeks in the CRASH study [11]. However, it is still

*Corresponding author: Dr. M. Aibiki, Department of Emergency Medicine Ehime University, Shitsukawa 454, Tohon, 791-0295, Ehime, Japan, E-mail: kurt.kraetschmer@aon.at

Received June 10, 2013; Accepted September 11, 2013; Published Septembe 16, 2013

Citation: Aibiki M, Umakoshi K, Ohtsubo S, Kikuchi S, Matsumoto H, et al. (2013) Effects of Dexamethasone on Pulmonary Oxygenation Impairments in Therapeutic Hypothermia for Patients with Traumatic Brain Injury. J Neurol Neurophysiol 4: 164. doi:10.4172/2155-9562.1000164

Copyright: (c) 2013 Aibiki M et al.This is an open-access article distributed under the terms of the Creative Commons Attribution License, which permits unrestricted use, distribution, and reproduction in any medium, provided the original author and source are credited. 
Citation: Aibiki M, Umakoshi K, Ohtsubo S, Kikuchi S, Matsumoto H, et al. (2013) Effects of Dexamethasone on Pulmonary Oxygenation Impairments in Therapeutic Hypothermia for Patients with Traumatic Brain Injury. J Neurol Neurophysiol 4: 164. doi:10.4172/2155-9562.1000164

uncertain whether steroid application is effective for lung injury during hypothermic therapy for traumatic brain-injured patients. We have raised a possibility in a preliminary study that dexamethasone might have a preventive effect for lung injury during hypothermic therapy for brain-injured patients [12]. Therefore, we examined retrospectively in this study whether dexamethasone has effects of reducing the rate of pneumonia and improving oxygenation impairments in TBI patients treated with therapeutic hypothermia.

\section{Subjects and Materials}

\section{General}

This retrospective study analyzed the data obtained from 1999 to 2009, which included the data of the Kagawa University Hospital and the Ehime University Hospital. Hypothermic and normothermic therapies in the two institutes were performed according to the same protocol except the administration of dexamethasone.

Inclusion criteria included a Glasgow Coma Scale (GCS) score less than and equal to eight on admission to the emergency room and evidence of injury on the computed tomographic scanning of the brain. The characteristics of the patients are shown in Tables 1 and 2. The GCS

\begin{tabular}{|c|c|c|c|c|c|c|c|c|c|}
\hline & Age & Gend. & Diag. & GCS & ST & GOS & $\begin{array}{c}\text { CT } \\
\text { Class. }\end{array}$ & $\begin{array}{l}\text { Pupil } \\
\text { Abnon }\end{array}$ & Dex. \\
\hline \multirow{2}{*}{1} & \multirow{2}{*}{76} & \multirow{2}{*}{ M } & C C & \multirow{2}{*}{6} & \multirow{2}{*}{$(+)$} & \multirow{2}{*}{ V } & \multirow{2}{*}{5} & \multirow{2}{*}{$(-)$} & $(+)$ \\
\hline & & & E H & & & & & & $(+)$ \\
\hline \multirow{2}{*}{2} & \multirow{2}{*}{19} & \multirow{2}{*}{ M } & E H & \multirow{2}{*}{5} & \multirow{2}{*}{ ND } & \multirow{2}{*}{ SD } & \multirow{2}{*}{4} & \multirow{2}{*}{$(+)$} & $(+)$ \\
\hline & & & $\mathrm{SH}$ & & & & & & $(+)$ \\
\hline 3 & 70 & $M$ & $\mathrm{EH}$ & 5 & $(+)$ & $D$ & 5 & $(+)$ & $(+)$ \\
\hline 4 & 38 & $\mathrm{~F}$ & TSAH & 5 & ND & GR & 2 & $(-)$ & $(+)$ \\
\hline \multirow{2}{*}{5} & \multirow{2}{*}{65} & \multirow{2}{*}{ M } & C C & \multirow{2}{*}{4} & \multirow{2}{*}{$(+)$} & \multirow{2}{*}{ D } & \multirow{2}{*}{5} & \multirow{2}{*}{$(+)$} & $(+)$ \\
\hline & & & $\mathrm{ICH}$ & & & & & & $(+)$ \\
\hline 6 & 76 & $M$ & $\mathrm{ICH}$ & 6 & $(+)$ & V & 5 & $(-)$ & $(+)$ \\
\hline 7 & 27 & $M$ & C C & 7 & ND & GR & 2 & $(-)$ & $(+)$ \\
\hline 8 & 4 & $\mathrm{~F}$ & C C & 6 & ND & SD & 4 & $(-)$ & $(+)$ \\
\hline 9 & 16 & $\mathrm{~F}$ & DAI & 6 & ND & $\mathrm{MD}$ & 2 & $(-)$ & $(+)$ \\
\hline 10 & 18 & $M$ & $\mathrm{SH}$ & 5 & $(+)$ & D & 5 & $(+)$ & $(+)$ \\
\hline 11 & 16 & M & C C & 8 & ND & GR & 2 & $(-)$ & $(+)$ \\
\hline *12 & 19 & $\mathrm{~F}$ & DAI & 6 & ND & GR & 1 & $(+)$ & $(-)$ \\
\hline \multirow{2}{*}{13} & \multirow{2}{*}{80} & \multirow{2}{*}{ 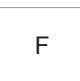 } & TSAH & \multirow{2}{*}{6} & \multirow{2}{*}{ ND } & \multirow{2}{*}{ SD } & \multirow[b]{2}{*}{2} & \multirow{2}{*}{$(+)$} & \multirow{2}{*}{$(-)$} \\
\hline & & & CC & & & & & & \\
\hline 14 & 79 & $\mathrm{~F}$ & $\mathrm{PH}$ & 8 & $(+)$ & SD & 2 & $(+)$ & $(-)$ \\
\hline 15 & 80 & $\mathrm{~F}$ & TSAH & 6 & ND & SD & 2 & $(+)$ & $(-)$ \\
\hline & & & CC & & & & & & \\
\hline 16 & 7 & $M$ & CC & 8 & $\mathrm{ND}$ & GR & 1 & $(+)$ & $(-)$ \\
\hline
\end{tabular}

Table1: Normothermia Group

Abbreviations: Gend: Gender; F: Female; M: Male; GCS: Glasgow Come Scale; ST: Surgical treatment; GOS: Glasgow Outcome Scale; Pupil abn, on ad.,: Pupil abnormality on admission; Dex: Dexamethazone; CC: Cerebral contusion; EH: Epidural hematoma; SH: Subdural hematoma; TSAH:

Traumatic subarachinoid hemorrhage; ICH: Intra-cerebral hemorrhage; DAI: Diffuse axonal injury; PH: Pontine hemorrhage; ND: Not done; D: Death; V: Vegetative; SD: Severe disability; MD: Moderate disability; GR: Good recovery; CT: Computed tomography;

CT class: 1 , no visible evidence of injury; 2 , cisterns present with a midline shift less than $5 \mathrm{~mm}$ and no lesion more than $25 \mathrm{ml}$; 3 , cisterns compressed or absent; 4 , midline shift of more than $5 \mathrm{~mm} ; 5$, a lesion requiring surgical evacuation.

Pupillary abnormalities were defined as abnormalities in size or light response in one or both pupils. An asterisk shows a case of determining neutrophil functions during the normothermic therapy. scores of the patients ranged from 3 to 8 on admission.

Patients who had abdominal or chest trauma were excluded from the study $(\mathrm{N}=6)$. Patients who were admitted to the hospital more than $8 \mathrm{hrs}$ after the injury were also excluded $(\mathrm{N}=5)$. Other exclusion criteria were as follows: aspiration already on admission $(\mathrm{N}=4)$, severe hypoxia on admission $(\mathrm{N}=3)$, brain death within 48 hours $(\mathrm{N}=4)$, incomplete serial data of $\mathrm{C}$-reactive protein and arterial blood gas analysis $(\mathrm{N}=7)$.

Moderate hypothermia or normothermia was induced within $6 \mathrm{hrs}$ after the injury and was maintained by a surface cooling after administration of midazolam at the dose of 3 to $7 \mu \mathrm{g} / \mathrm{kg} / \mathrm{min}$, vecuronium at the dose of 2 to $4 \mathrm{mg} / \mathrm{hr}$, and buprenorphine at the dose of 0.4 to $0.6 \mathrm{mg} /$ day. These agents were administered until the end of the rewarming. All patients were ventilated artificially to adjust Paco 2 at the level of 30 to $35 \mathrm{mmHg}$, which was not corrected for body temperature ( $\alpha$-stat management). Body temperatures were monitored at the rectum or the bladder. After the hypothermic phase, patients were gradually rewarmed at the rate of approximately $1^{\circ} \mathrm{C}$ per day. The rewarming process was started if there were no signs of brain swelling on computed tomographic findings and no intracranial pressure (ICP) elevation. The duration of hypothermic period was usually 3 to 4 days and the duration of the rewarming phase lasted for 4 to 5 days, thus the period of the hypothermic therapy was usually 7 to 9 days.

\section{Treatment protocol}

Subdural, epidural, or intracerebral hematomas compressing the brain were evacuated as soon as possible by neurosurgeons. Mean arterial pressure was maintained between 90 and $100 \mathrm{mmHg}$ to keep the cerebral perfusion pressure more than $70 \mathrm{mmHg}$. In all patients, 600 to $800 \mathrm{~mL}$ of $10 \%$ glycerol was administered daily for 7 days. This dosage of the agent adheres to our protocol for brain-injured patients with brain swelling. ICP monitoring (Codman ICP sensor ${ }^{\mathrm{TM}}$, Johnson and Johnson, Raynham, MA) was performed in twelve patients in the normothermic group and twenty-one patients in the hypothermic group. During the study, no patients in either group received diphenylhydantoin.

\section{Dexamethasone adminisatration}

In accordance with our protocol prior to 2001, dexamethasone (D) was used for the purpose of potential attenuation in brain swelling to patients in hypothermic and normothermic groups. From 2001, we discontinued the use of $\mathrm{D}$ in brain-injured patients according to a guideline [6]. Thereafter, we faced increases in the rate of pneumonia in patients treated with therapeutic hypothermia, which was accompanied by an activated neurophil function during hypothermic therapy. Accordingly, we administered D in several brain-injured patients to expect potential preventive effects for pulmonary complication during the therapy. Based on such preliminary data, we have reported that neutrophils might have a role in acute lung injury during hypothermic therapy [12]. The method of D for the patients was $0.15 \mathrm{mg} / \mathrm{kg}$ for approximately 7 days. The dose of dexamethasone was based on a previous paper [13], on the clinical application, we had modified the dose and administered duration of the agent. In our previous studies [4,5], dexamethasone was administered to hypothermic and normothermic groups, but in other preliminary studies $[7,12]$, the agent was given depending on each physician in charge.

\section{Assessment of neurologic outcome}

Independent neurosurgeons who were not aware of the study presented here determined the neurologic outcome 6 months after 
injury. The neurologic outcome was graded according to the Glasgow Outcome Scale [14] (GOS: 14): 1, death; 2, vegetative state; 3, severe disability (unable to live independently but able to follow commands); 4 , moderate disability (ability to live independently but unable to return to work or school); 5 , good recovery (able to return to work or school).

\section{Complications in each group}

The diagnosis for pneumonia was made from purulent sputum sampling from an intratracheal tube, positive X-ray findings including lung consolidations, and/or positive cultures. After the admission, a first generation cephalosporin or ampicilin/sulbactum was administered, in accordance with the protocol of our department. Blood examinations and sputum cultures were routinely performed at least every two days. Depending on results of the gram-stain, we changed the antibiotics empirically; otherwise, we would wait for culture results and sensitivity results to various antibiotics. The overall rate of occurrence of pneumonia did not differ significantly between the two groups $(9 / 23$ in hypothermia group; 4/16 in normothermia group, Table 3 ).

\section{Neutrophil functions}

\begin{tabular}{|c|c|c|c|c|c|c|c|c|c|}
\hline & $\operatorname{Age}(\mathrm{Y})$ & Gend. & Diag. & GCS & ST & Gos & CTClass. & $\begin{array}{l}\text { Pupil } \\
\text { Abn.on } \\
\text { ad. }\end{array}$ & Dex. \\
\hline \multirow{2}{*}{1} & \multirow{2}{*}{12} & \multirow{2}{*}{ M } & C C & \multirow{2}{*}{5} & \multirow{2}{*}{$(+)$} & \multirow{2}{*}{$\mathrm{MD}$} & \multirow{2}{*}{5} & \multirow{2}{*}{$(+)$} & $(+)$ \\
\hline & & & E H & & & & & & $(+)$ \\
\hline \multirow{2}{*}{2} & \multirow{2}{*}{67} & \multirow{2}{*}{ M } & EH & \multirow{2}{*}{5} & \multirow{2}{*}{$(+)$} & \multirow{2}{*}{ SD } & \multirow{2}{*}{5} & \multirow{2}{*}{$(+)$} & $(+)$ \\
\hline & & & $\mathrm{SH}$ & & & & & & $(+)$ \\
\hline 3 & 17 & M & EH & 7 & $(+)$ & GR & 5 & $(+)$ & $(+)$ \\
\hline 4 & 16 & M & $\mathrm{SH}$ & 8 & $(+)$ & GR & 5 & $(-)$ & $(+)$ \\
\hline \multirow{2}{*}{5} & \multirow{2}{*}{9} & \multirow{2}{*}{ M } & C C & \multirow{2}{*}{5} & \multirow{2}{*}{$(+)$} & \multirow{2}{*}{ GR } & \multirow{2}{*}{5} & \multirow{2}{*}{$(+)$} & $(+)$ \\
\hline & & & $\mathrm{ICH}$ & & & & & & $(+)$ \\
\hline 6 & 52 & M & $\mathrm{ICH}$ & 6 & $(+)$ & $\mathrm{MD}$ & 5 & $(+)$ & $(+)$ \\
\hline 7 & 57 & $\mathrm{~F}$ & $\mathrm{ICH}$ & 5 & $(+)$ & SD & 5 & $(-)$ & $(+)$ \\
\hline \multirow{2}{*}{8} & \multirow{2}{*}{48} & \multirow{2}{*}{ M } & C C & 7 & & & & & $(+)$ \\
\hline & & & $\mathrm{ICH}$ & 1 & $(+)$ & $G R$ & 5 & $(-)$ & $(+)$ \\
\hline & & & DAI & & & & & & $(+)$ \\
\hline 9 & 18 & M & TSAH & 7 & ND & GR & 2 & $(-)$ & $(+)$ \\
\hline 10 & 22 & $M$ & $\mathrm{SH}$ & 6 & $(+)$ & $M D$ & 5 & (t) & $(+)$ \\
\hline & & & C C & & & WIV & $\mathrm{J}$ & (1) & $(+)$ \\
\hline 11 & 76 & M & $\mathrm{ICH}$ & 5 & $(+)$ & $\mathrm{MD}$ & 5 & $(+)$ & $(+)$ \\
\hline 12 & 72 & M & $\mathrm{ICH}$ & 3 & ND & $\mathrm{D}$ & 3 & $(+)$ & $(+)$ \\
\hline 13 & 27 & M & $C \mathrm{C}$ & 8 & ND & GR & 2 & $(-)$ & $(+)$ \\
\hline 14 & 11 & $\mathrm{~F}$ & C C & 4 & ND & GR & 2 & $(+)$ & $(+)$ \\
\hline 15 & 17 & $\mathrm{~F}$ & $\mathrm{ICH}$ & 5 & ND & GR & 2 & $(+)$ & $(+)$ \\
\hline *16 & 17 & M & TSAH & 7 & ND & $\mathrm{GR}$ & 4 & $(+)$ & $(+)$ \\
\hline & 69 & $F$ & $\mathrm{SH}$ & 8 & חת & $\mathrm{SR}$ & 2 & (+) & $(+)$ \\
\hline 17 & 69 & F & $\mathrm{CC}$ & 8 & ND & SD & 2 & $(+)$ & \\
\hline & & & TSAH & & & & & & $(-)$ \\
\hline${ }^{*} 18$ & 19 & $\mathrm{~F}$ & $\mathrm{SH}$ & 4 & $(+)$ & GR & 5 & $(+)$ & \\
\hline & & & TSAH & & & & & & \\
\hline 19 & 62 & M & CC & 6 & $(+)$ & D & 5 & $(-)$ & $(-)$ \\
\hline & & & $\mathrm{SH}$ & & & & & & \\
\hline & & & TSAH & & & & & & \\
\hline 20 & 33 & M & $\mathrm{SH}$ & 6 & ND & MD & 3 & $(-)$ & $(-)$ \\
\hline 21 & 72 & $\mathrm{~F}$ & $\mathrm{Cl}$ & 8 & $(+)$ & $M D$ & 5 & $(+)$ & $(-)$ \\
\hline 22 & 45 & M & $\mathrm{IH}$ & 8 & $(+)$ & $M D$ & 5 & $(+)$ & $(-)$ \\
\hline${ }^{*} 23$ & 17 & $\mathrm{~F}$ & TSAH & 4 & ND & SD & 2 & $(+)$ & $(-)$ \\
\hline
\end{tabular}

Abbreviations are referred to those in the Table 1.

Table 2: Asterisks show cases of examining neutrophil functions during hypothermic therapy.
Blood samples were obtained from brain-injured patients by venipuncture and collected in heparinized test tubes to prevent clotting. Polymorphonuclear leukocytes (PMNs) were prepared on Ficoll-Hypaque gradients. A $5 \mathrm{ml}$ of blood was layered on $3 \mathrm{ml}$ of roomtemperature Ficoll-Hypaque in conical plastic disposable tubes. After centrifugation ( 25 minutes, $250 \mathrm{x} \mathrm{g}$ ), the lymphocyte/mononuclear band was removed. PMNs were located in the next layer above the RBC pellet and could be collected easily. After centrifugation ( $5 \mathrm{~min}, 250 \mathrm{x}$ g), contaminating RBCs were lysed with $9.0 \mathrm{ml}$ of cold distilled water, quickly followed by $1.0 \mathrm{ml}$ of a $10 \mathrm{x}$ concentrated buffer solution. The final cell pellet was suspended in N-2-hydroxy ethyl piperazine-N'2-ethane sulfonic acid (HEPES; Sigma Chemical Co., St. Louis, Mo.), buffered tissue culture medium RPMI 1640 (Gibco, Grand Island, NY), pH 7.0, plus $0.1 \%$ gelatin (Difco Laboratories, Detroit, Mich.) to a density of $2.5 \times 10^{6}$ cells $/ \mathrm{ml}$.

Phagocytic function was measured as numbers of phagocytic latex beads using flow-cytometry [15]. Bactericidal function was determined by the numbers of fluorescence of neutrophils using flowcytometry in PMA (phorbol myristate acetate) solution after adding 2', 7'-dichloroflure diacetate (DCFH-DA) [16].

\section{Statistical analysis}

Data are expressed as mean $\pm \mathrm{SD}$. The baseline characteristics and outcomes in the two groups were compared with use of a chi-squared test or Mann-Whitney $U$ tests as appropriate. Other statistical analyses were performed using analysis of variance followed by Scheffe's F-tests for comparisons within a group and Mann-Whitney U tests or KruskalWallis tests for comparisons among the groups. A p value less than 0.05 was considered as significant.

\section{Results}

\section{Patients' background}

Demographic data of each patient were shown in Table 1 and 2. There were not any differences in the antibiotic use, the frequency of physio-therapy or oral care between the two groups (data not shown) (Figure 1).

Table 3 shows comparisons of background data between the hypothermic and normothermic groups. Although there were no significant differences in the demographic data or the rate of pneumonia

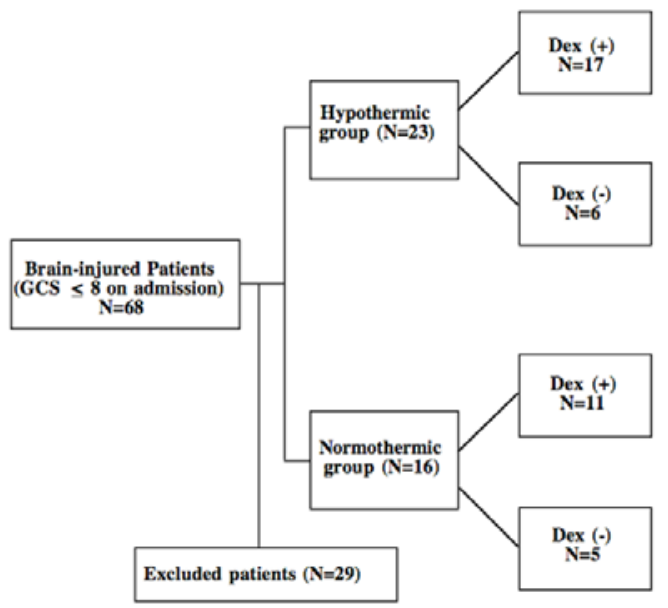

Figure 1: Flow chart of the patients 
between the two groups, the neurological outcome in hypothermic group was more favorable than that in normothermic group.

Table 4 demonstrates the comparisons of patients' backgrounds between normothermia and hypothermic groups with or without dexamethasone (D) administration. No significant differences in the demographic data were found between the two groups with or without $\mathrm{D}$ [17-19]. The occurrence of pneumonia in hypothermic group with $\mathrm{D}$ did not differ from that in the normothermic group with D. However, the rate of pneumonia in hypothermia group without $\mathrm{D}$ was much higher than those in the normothermia without $\mathrm{D}$.

Time course changes in CRPs and P/F ratios in hypothermic and normothermic groups with or without Dexamethasone

Comparisons of CRPs and P/F ratios in the two groups are shown in Figure 2. In the upper panel, there were significant elevations in CRPs, which was followed by profound impairments in $\mathrm{P} / \mathrm{F}$ ratios in patients not receiving the steroid in hypothermic group. In the lower panel, there were no significant differences in CRPs or P/F ratios in either groups being administered dexamethasone.

\section{Changes in neutrophil functions in brain-injured patients}

In Figure 3, changes of phagocytic function, CRP and P/F ratio in brain-injured patients in hypothermic group are depicted. Two patients in the hypothermia group, not treated with $\mathrm{D}$, showed activated neutrophil phagocytic functions followed by severe deteriorations in $\mathrm{P} / \mathrm{F}$ ratios. A patient in the hypothermic group, given the steroid, had depressed phagocytic function after the steroid treatment but did not show $\mathrm{P} / \mathrm{F}$ ratio reductions below $280 \mathrm{mmHg}$. accompanied by improved neurological outcomes during hypothermic therapy. Thus, in the future we need to test a hypothesis that dexamethasone can be used as an agent for the treatment of lung injury during hypothermic therapy for brain-injured patients.

\section{Role of neutrophils in pulmonary oxygenation impairment} during therapeutic hypothermia

PMN functions during hypothermia have been demonstrated to attenuate the receptor-dependent mechanism through protein kinase C level, but conversely are enhanced when elevating the temperature in the receptor-independent pathway [20]. Thus, neutrophil functions

\begin{tabular}{|c|c|c|c|}
\hline & $\begin{array}{c}\text { Normothermia } \\
\text { group (N=16) }\end{array}$ & $\begin{array}{c}\text { Hypothermia } \\
\text { group (N=23) }\end{array}$ & p value \\
\hline Age & $39 \pm 30$ & $37 \pm 24$ & 0.72 \\
\hline BW & $60 \pm 25$ & $65 \pm 22$ & 0.67 \\
\hline Gender (F/M) & $7 / 9$ & $7 / 16$ & 0.4 \\
\hline GCS on admission & $6.1 \pm 1.2$ & $5.9 \pm 1.4$ & 0.64 \\
\hline CT Class & $3.2 \pm 1.4$ & $4 \pm 1.3$ & 0.1 \\
\hline Inj Type (Tra/non-Tra) & $21 / 2$ & $15 / 1$ & 0.7 \\
\hline ST(+/-) & $6 / 10$ & $14 / 9$ & 0.26 \\
\hline Pupil abn. (+/-) & $7 / 9$ & $8 / 15$ & 0.6 \\
\hline Pneumonia Dev. (+/-) & $4 / 12$ & $9 / 14$ & 0.35 \\
\hline Dexamethasone (+/-) & $11 / 5$ & $17 / 6$ & 0.9 \\
\hline GoS (GR+MD/SD+V+D) & $6 / 10$ & $17 / 6$ & $0.02^{*}$ \\
\hline Mean $\pm S D$ & & & \\
\hline
\end{tabular}

Table 3. Comparisons in Demographic Data and Neurological prognosis between

Normothermic and Hypothermic groups

Note that neurological outcome in hypothermic group was better than that in normothermic group, while the other patients' profiles were not different between the two groups. CT classification and abbreviations are referred to those in Table 1.
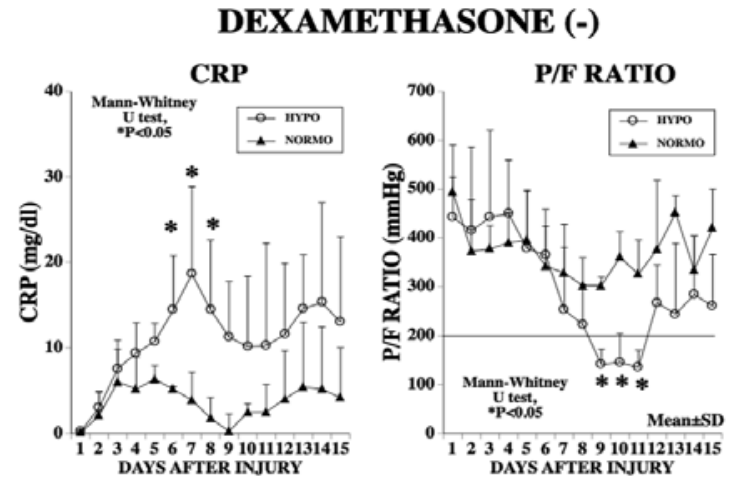

Figure 2. Comparisons of CRPs and P/F ratios

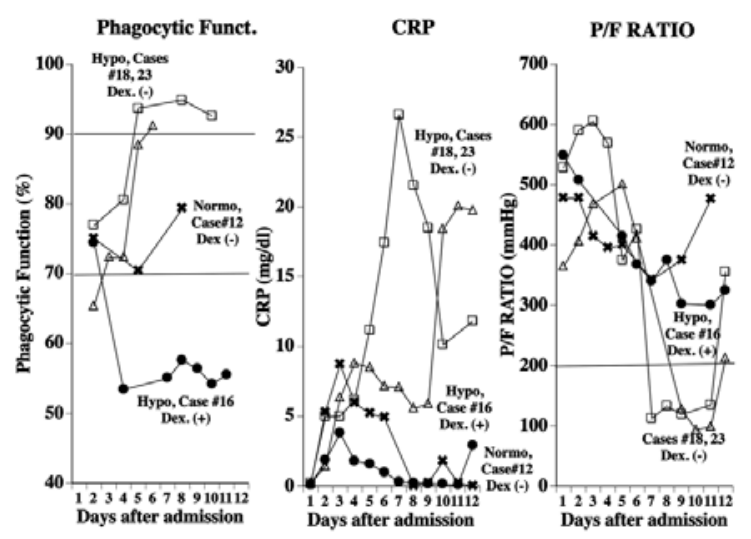

Figure 3. CRP and P/F ratio in brain-injured patients

\begin{tabular}{|c|c|c|c|}
\hline Dexamethasone (+) & $\begin{array}{l}\text { Normothermia } \\
\text { group }(\mathrm{N}=11)\end{array}$ & $\begin{array}{l}\text { Hypothermia } \\
\text { group }(N=17) p\end{array}$ & value \\
\hline Age & $39 \pm 25$ & $36 \pm 24$ & 0.61 \\
\hline BW & $59 \pm 21$ & $61 \pm 18$ & 0.7 \\
\hline Gender (F/M) & $3 / 8$ & $4 / 13$ & 0.57 \\
\hline GCS & $5.7 \pm 1$ & $5.9 \pm 2$ & 0.65 \\
\hline $\mathrm{ST}(+/-)$ & $5 / 6$ & $9 / 8$ & 0.51 \\
\hline Pupil abn. (+/-) & $4 / 7$ & $11 / 6$ & 0.14 \\
\hline Pneumonia Dev. $(+/-)$ & $3 / 8$ & $\begin{array}{l}4 / 13 \\
\text { Mean } \pm S D\end{array}$ & 0.82 \\
\hline Dexamethasone (-) & $\begin{array}{l}\text { Normothermia } \\
\text { group }(N=5)\end{array}$ & $\begin{array}{c}\text { Hypothermia } \\
\text { group }(\mathrm{N}=6)\end{array}$ & $p$ value \\
\hline Age & $53 \pm 35$ & $41 \pm 22$ & 0.43 \\
\hline BW & $50 \pm 29$ & $65 \pm 22$ & 0.5 \\
\hline Gender (F/M) & $4 / 1$ & $3 / 3$ & 0.2 \\
\hline GCS & $6.8 \pm 1.1$ & $6 \pm 1.8$ & 0.46 \\
\hline $\mathrm{ST}(+/-)$ & $1 / 4$ & $4 / 2$ & 0.1 \\
\hline Pupil abn. (+/-) & $5 / 0$ & $4 / 2$ & 0.1 \\
\hline Pneumonia Dev. (+/-) & $1 / 4$ & $\begin{array}{l}5 / 1 \\
\text { Mean } \pm S D\end{array}$ & $0.03^{*}$ \\
\hline
\end{tabular}

Table 4: Comparisons in Demographic Data and Occurrence Rate of Pneumonia between Normothermic and Hypothermic groups with or without Dexamethasone Treatment.

Note that although there was no difference in the rate of pneumonia between hypothermic and normothermic groups with steroid treatment, the occurrence rate of pneumonia in hypothermic group without $D$ was higher than that in normothermic group not being given $\mathrm{D}$. Abbreviations are referred to those in Table1. 
Citation: Aibiki M, Umakoshi K, Ohtsubo S, Kikuchi S, Matsumoto H, et al. (2013) Effects of Dexamethasone on Pulmonary Oxygenation Impairments in Therapeutic Hypothermia for Patients with Traumatic Brain Injury. J Neurol Neurophysiol 4: 164. doi:10.4172/2155-9562.1000164

during hypothermic condition may be regulated by mechanisms more complicated than previously recognized. However, the rewarming after hypothermic treatment causes profound augmentation of interleukin- 8 production in LPS-treated human endothelial cells, leading to PMN degranulation [8]. In this study, we have shown that impairments in pulmonary oxygen occurred especially after the rewarming phase following the hypothermic period. The present findings may support the previous study showing neutrophil activation by the rewarming from the hypothermic treatment [8].

Glucocorticoids, including dexamethasone, have been traditionally recognized as immunosuppressive hormones [21], and they downregulate the expression of genes involved in neutrophil trafficking to inflamed tissues $[22,23]$.

\section{Effects of dexamethasone on pulmonary oxygenation impairment during hypothermic therapy}

It is well known that trauma including head injury is complicated with pulmonary involvements, which may be resulted from systemic inflammatory responses [24]. We have previously shown that in the rabbits, hypothermia induced by surface cooling causes sympathetic activation even from $36^{\circ} \mathrm{C}$, peaking at $28^{\circ} \mathrm{C}$ [25], which means that surface cooling itself can cause vigorous stress to the animals. Also in humans, we have reported activated IL- 6 and IL- 8 productions in patients with accidental hypothermia [26]. Thus, we need to attenuate such physiological stress responses to surface cooling during hypothermic therapy using sedatives, narcotics and a muscle relaxant [27]. However, it is still unclear whether such an anesthetic procedure could completely suppress the stress responses during the hypothermic therapy. On the other hand, in septic rats, hypothermia causes an interleukin-6 overproduction leading to increases in mortality [28]. Glucocorticoid has been demonstrated to prevent acute lung injury, which is associated with neutrophil activation, occurring in the latephase in critical trauma patients [10]. In the present study, we have demonstrated that dexamethasone prevented the deteriorations of pulmonary oxygenation during hypothermic therapy for braininjured patients. Thus, further research is required to define whether dexamethasone has preventive effects on acute lung injury involving leukocyte activations after hypothermic therapy for brain-injured patients.

\section{Limitation of this study}

We have demonstrated the limited data of CRP and P/F ratio in hypothermic and normothermic groups. Furthermore, we included patients with the various sorts of traumatic brain injury, which structured heterogenetic groups. Thus, in the future, a randomized and large-scale study is needed to define a role of neutrophil and dexamethasone in acute lung injury after therapeutic hypothermia for brain-injured patients.

\section{Conclusion}

This is the first report suggesting a potential role of neutrophils in the development of pulmonary oxygenation impairments after hypothermic therapy for brain-injured patients and also showing attenuated effects of dexamethasone on such sequelae.

\section{References}

1. Clifton GL, Miller ER, Choi SC, Levin HS, McCauley S, et al. (2001) Lack of effect of induction of hypothermia after acute brain injury. N Engl J Med. 22: 556-563

2. Shiozaki T, Hayakata T, Taneda M, Nakajima Y, Hashiguchi N, et al. (2001)
A multicenter prospective randomized controlled trial of the efficacy of mild hypothermia for severely head injured patients with low intracranial pressure. Mild Hypothermia Study Group in Japan. J Neurosurg. 94: 50-54

3. Polderman $\mathrm{KH}$ (2004) Application of therapeutic hypothermia in the intensive care unit. Opportunities and pitfalls of a promising treatment modality--Part 2 Practical aspects and side effects. Intensive Care Med 30: 757-769.

4. Aibiki M, Maekawa S, Ogura S, Kinoshita Y, Kawai N, et al. (1999) Effect of moderate hypothermia on systemic and internal jugular plasma IL-6 levels after traumatic brain injury in humans. J Neurotrauma 16: 225-232.

5. Aibiki M, Maekawa S, Yokono S (2000) Moderate hypothermia improves imbalances of thromboxane A2 and prostaglandin 12 production after traumatic brain injury in humans. Crit Care Med 28: 3902-3906.

6. Procaccio F, Stocchetti N, Citerio G, Berardino M, Beretta L, et al. (2000) Guidelines for the treatment of adults with severe head trauma (part II). Criteria for medical treatment. J Neurosurg Sci 44: 11-18.

7. M Aibiki, S Ohtsubo, K Umakoshi, S Kikuchi, H Matsumoto (2008) Role of Nutrophils and Preventive Effect of Dexamethasone on Pulmonary Complications During Hypothermic Therapy for Brain-Injured Patients. Resuscitation Science Symposium Program, 47S.

8. Finn A, Moat N, Rebuck N, Klein N, Strobel S, et al. (1993) Changes in neutrophil CD11b/CD18 and L-selectin expression and release of interleukin 8 and elastase in paediatric cardiopulmonary bypass. Agents Actions 38: 44-46

9. Nakamura E, Kitagawa Y, Ozawa S, Suda K, Ando N, et al. (2006) Role of steroid administration to reduce inflammation after thoracotomy in a rat surgical stress model. J Surg Res 135: 364-369.

10. Koontz CS, Higdon KK, Ploger TL, Dart BW 4th, Richart CM, et al. (2006) Glucocorticoid rescue for late-phase acute respiratory distress syndrome in trauma/surgical critical care patients. Am Surg 72: 644-648.

11. Roberts I, Yates D, Sandercock P. Farrell B, Wasserberg J, et al. (2004) Effect of intravenous corticosteroids on death within 14 days in 10008 adults with clinically significant head injury (MRC CRASH trial): randomised placebocontrolled trial. Lancet 364: 1321-1328.

12. T Nishiyama, M Aibiki, S Maekawa, S Ohtsubo, Y Shirakawa (2006) A Role of Neutrophils in Pulmonary Complications during Hypothermic Therapy in Braininjured Patients. Shock 25: 28S.

13. Hoyt HJ, Goldstein FP, Reigel DH, Holst R (1972) Clinical evaluation of highly water-soluble steroids in the treatment of cerebral edema of traumatic origin (a double blind study). Pharmacol Ther 13: 141.

14. Jennett B, Bond M (1975) Assessment of outcome after severe brain damage Lancet 1: 480-484

15. Dunn PA, Tyrer HW (1981) Quantitation of neutrophil phagocytosis, using fluorescent latex beads. Correlation of microscopy and flow cytometry. J Lab Clin Med 98: 374-381.

16. Bass DA, Parce JW, Dechatelet LR, Szejda P, Seeds MC, et al. (1983) Flow cytometric studies of oxidative product formation by neutrophils: a graded response to membrane stimulation. J Immunol 130: 1910-1917.

17. Tsao N, Hsu HP, Wu CM, Liu CC, Lei HY (2001) Tumour necrosis factor-alpha causes an increase in blood-brain barrier permeability during sepsis. $\mathrm{J}$ Med Microbiol 50: 812-821.

18. Stocchetti N (2005) Brain and sepsis: functional impairment, structural damage and markers. Anesth Analg 101: 1463-1464.

19. Aibiki M (2004) Practical aspects and prevention of complications during therapeutic hypothermia. Intensive Care Med 30: 2286.

20. Fröhlich D, Wittmann S, Rothe G, Sessler DI, Vogel P, et al. (2004) Mild hyperthermia down-regulates receptor-dependent neutrophil function. Anesth Analg 99: 284-292.

21. Rhen T, Cidlowski JA (2005) Antiinflammatory action of glucocorticoids--new mechanisms for old drugs. N Engl J Med 353: 1711-1723.

22. Weber PS, Toelboell T, Chang LC, Tirrell JD, Saama PM, et al. (2004) Mechanisms of glucocorticoid-induced down-regulation of neutrophil L-selectin in cattle: evidence for effects at the gene-expression level and primarily on blood neutrophils. J Leukoc Biol 75: 815-827.

23. Weber PS, Madsen-Bouterse SA, Rosa GJ, Sipkovsky S, Ren X, et al. (2006) Analysis of the bovine neutrophil transcriptome during glucocorticoid treatment Physiol Genomics 28: 97-112. 
Citation: Aibiki M, Umakoshi K, Ohtsubo S, Kikuchi S, Matsumoto H, et al. (2013) Effects of Dexamethasone on Pulmonary Oxygenation Impairments in Therapeutic Hypothermia for Patients with Traumatic Brain Injury. J Neurol Neurophysiol 4: 164. doi:10.4172/2155-9562.1000164

Page 6 of 6

24. Salim A, Martin M, Constantinou C, Sangthong B, Brown C, et al. (2006) Acute respiratory distress syndrome in the trauma intensive care unit: Morbid but not mortal. Arch Surg 141: 655-658.

25. Xu H, Aibiki M, Seki K, Ogura S, Yokono S, et al. (2000) Effects of induced hypothermia on renal sympathetic nerve activity and baroreceptor reflex in urethane-anesthetized rabbits. Crit Care Med 28: 3854-3860.
26. Aibiki M, Maekawa S, Nishiyama T, Seki K, Yokono S (1999) Activated cytokine production in patients with accidental hypothermia. Resuscitation 41: 263-268.

27. Aibiki M (2000) Hypothermia and head injury. J Neurosurg 92: 1074-1076

28. Torossian A, Ruehlmann S, Middeke M, Sessler DI, Lorenz W, et al. (2003) Deleterious effects of mild hypothermia in septic rats are ameliorated by granulocyte colony-stimulating factor. Anesthesiology 99: 1087-1092. 